\title{
POLÍTICAS E GESTÃO DA EDUCAÇÃO: UMA ANÁLISE DA TRAJETÓRIA DA PESQUISA ${ }^{1}$
}

\section{Policies and Management of Education: an Analysis of the Research Trajectory}

\author{
Ana Maria Eyng ${ }^{2}$ \\ Maria Lourdes $\mathrm{Gisi}^{3}$ \\ Romilda Teodora Ens ${ }^{4}$
}

\section{Resumo}

O presente trabalho resulta da análise feita de dissertações e teses da Área de Educação sobre políticas, gestão da educação e formação de professores. A fundamentação, amadurecimento e consolidação de uma mudança política requer a discussão que a pesquisa favorece, sobretudo nos trabalhos de teses e dissertações. Com o intuito de verificar o avanço teórico atingido na área de educação sobre a temática é que se buscou investigar a trajetória das pesquisas de dissertações e teses defendidas entre 1999 e 2003 vinculados à formação de professores na Região Sul do Brasil.

Palavras-chave: Políticas educacionais; Gestão democrática; Formação de professores.

\section{Abstract}

The present study results from an analysis of dissertations and theses conceming policies, management of education and teacher education in the field of education. For the substantiation, maturing, and consolidation of political transformation, the discussion that research propitiates is required, above all the one found in dissertations and theses. The dissertations and theses defended between 1999 and 2003 associated with teacher education in the southem region of Brazil, were investigated with the intent of verifying the theoretical improvement accomplished on the subject, in the field of education. Keywords: Educational policies; Democratic management; Teacher education.

1 O presente artigo se apóia em trabalho apresentado no XIV Colóquio da AFIRSE Para um Balanço da Investigação em Educação de 1960 a 2005 - Teorias e Práticas - com resumo publicado no Livro do Colóquio. Lisboa: Porto Editora, fevereiro de 2006. v. 1, p. 78-79.

2 Professora Doutora do Programa de Mestrado em Educação da PUCPR. e-mail: ana.eyng@pucpr.br

3 Professora Doutora do Programa de Mestrado e Doutorado em Educação da PUCPR. e-mail: maria.gisi@pucpr.br

4 Coordenadora do Curso de Pedagogia da PUCPR. E-mail: romilda.ens@pucpr.br 


\section{Introdução}

O presente texto apresenta resultados da análise feita de dissertações e teses da Área de Educação, da região Sul do Brasil, sobre políticas educacionais, gestão da educação e formação de professores, no período de 1999 a 2003. O estudo analisa a relação entre os temas investigados e as reformas educacionais efetuadas nos anos 90 , considerando as novas orientações na legislação vigente. A consolidação de uma nova orientação política demanda tempo e isso pode ser observado no que se refere às mudanças determinadas na Lei de Diretrizes e Bases da Educação Nacional - LDB - Lei no 9.394 de 26 de dezembro de 1996. Mesmo sendo discutidas e implementadas desde 1997, considerando o tempo para o desenvolvimento de uma dissertação ou de uma tese, as repercussões das mudanças políticas só podem ser observadas nos resultados a partir de 1999. Justifica-se, portanto, a seleção da amostra investigada nesse estudo abrangendo as teses e dissertações defendidas na região no período de 1999 a 2003.

A investigação leva em consideração que as transformações econômicas e os avanços tecnológicos causaram profundas mudanças no mundo do trabalho e tiveram forte repercussão na formulação das políticas educacionais. No que se refere aos rumos da educação no país, têm-se por um lado a exigência de um novo perfil profissional com ênfase no desenvolvimento de competências e habilidades, por outro a proposição de novas formas de gestão educacional voltadas para maior eficiência.

Uma política educacional só pode ser compreendida no contexto da sociedade na qual ela se insere e, sendo esta sociedade organizada por um sistema capitalista, sua proposição está estreitamente articulada aos interesses econômicos e, portanto, às diretrizes propostas para este setor. Nessa perspectiva, é preciso situar a política educacional no contexto socioeconômico vigente, buscando compreender como este vem repercutindo no papel do Estado e, por conseguinte, na formulação das políticas públicas.

A crise econômica que ocorreu na década de 1970 ocasionou profundas mudanças na estrutura dos países capitalistas que passaram a ser alvo de um conjunto de reformas que se traduzem, principalmente, pela abertura das economias nacionais ao capital estrangeiro, desregulamentação dos mercados, privatizações de empresas públicas e corte nos gastos sociais, que, segundo Gómez (2000, p. 21), traduzem uma “[...] linguagem e um projeto dominante de globalização econômica [...] que tem por espaço natural o próprio mundo e que pretende auto- regular-se, sem interferências políticas nacionais, regionais e internacionais".

Os países da América Latina, em decorrência da sua imensa dívida externa, têm sido os mais atingidos por este projeto econômico afetando dire- 
tamente a formulação das políticas públicas e entre estas a educação. As transformações econômicas, o modo de acumulação flexível, a reestruturação produtiva provocaram mudanças significativas no mundo do trabalho e passaram a repercutir fortemente na definição das políticas educacionais. Segundo Azevedo (2001), as reformas educacionais que vêm sendo realizadas mundialmente têm em comum a tentativa de melhorar as economias pelo fortalecimento da relação entre escolarização, trabalho, produtividade, serviços e mercado (AZEVEDO, 2001).

É nesse contexto que se insere a aprovação da Lei maior de educação para o país, a Lei de Diretrizes e Bases da Educação Nacional - LDB - Lei no 9394/96 que, não explicitando claramente as suas diretrizes e as formas de implantação, deixou espaço para as reformas mais polêmicas, muitas orientadas por documentos do Banco Mundial, dando origem a uma vasta legislação complementar. Nessa perspectiva, o presente estudo se propõe analisar a trajetória das pesquisas nos trabalhos de teses e dissertações sobre políticas educacionais, as mudanças propostas para a gestão educacional e a formação de professores, a partir da Lei.

Inicialmente cabe fazer referência às reformas propostas para a educação superior no país - locus - de formação de professores. As reformas da educação superior podem ser sintetizadas em duas vertentes principais: uma de caráter institucional - pela conformação de diferentes instituições de ensino superior: universidades, centros universitários, faculdades e institutos, e pela apropriação de novas formas de gestão que incorporam os princípios gerenciais aplicados às empresas. A outra vertente está relacionada à formação profissional - em que se propõe uma formação voltada para o mercado, justificada pela necessidade de formação de um novo perfil profissional, em decorrência das mudanças no processo produtivo.

Gomes (2003) considera a diversificação institucional um dos aspectos centrais na nova estrutura do Sistema de Ensino Superior Brasileiro, a estrutura anterior da universidade de pesquisa que se materializou, formalmente, como modelo único, pelo menos como concepção, caracterizava-se pela indissociabilidade ensino/pesquisa/extensão e como locus privilegiado para o ensino, que só excepcionalmente deveria ser desenvolvido em instituições não universitárias.

Essa diversificação foi adotada como política de expansão da educação superior em função da demanda crescente de vagas que ocorreu com a desregulamentação das instituições de ensino privado que, sem controle público, são reguladas pelo mercado. A expansão destas instituições ocorreu não só pela contenção da expansão do setor público, mas devido à reconfiguração das exigências educacionais em relação à formação científica, tecnológica e cultural (DOURADO et al., 2003). 
A proposição de novas formas de gestão, de acordo com Lobato, teve como premissa "[...] a ineficiência dos aparatos estatais e a necessidade de diminuir o seu tamanho, introduzindo-se mecanismos de competição e de gestão voltados a resultados". Tal proposição tem como objetivo propiciar ao Estado a eficiência necessária para dar conta das novas demandas da economia globalizada. O problema que decorre desta estratégia é que a gestão voltada para a eficiência e para resultados ocorre "[...] numa competição por rendimentos individuais e em estratégias de adaptação, mais do que em responsabilidades políticas coletivas" (2004, p. 98-99).

A vertente relacionada à formação profissional - em que se propõe uma formação voltada para o mercado, levou as universidades, segundo Dourado et al. (2003, p. 19), "[...] a contribuir significativamente com a produção da mais-valia relativa, ou seja, ela deve formar profissionais e gerar tecnologias e inovações que sejam colocadas a serviço do capital produtivo". O que se busca é o desenvolvimento de competências e habilidades relacionadas ao trabalho e ao controle mais direto sobre o processo de formação e sua avaliação.

De acordo com Ramos (2001), o que está sendo configurado é um profissionalismo do tipo liberal e a sua base se encontra no princípio da adaptabilidade para a mobilidade permanente entre diferentes funções, entre diferentes empresas e também para o subemprego ou para o trabalho autônomo. Uma concepção de educação que busca propiciar melhores condições de adaptação ao meio.

Com a aprovação da Lei no. 9394/96, extinguem-se os currículos mínimos e se propõem Diretrizes Curriculares como norteadores na elaboração dos projetos pedagógicos dos cursos de graduação. Entre as atribuições das universidades contidas no artigo 53 da LDB consta no inciso II: "fixar os currículos dos seus cursos e programas, observadas as diretrizes gerais pertinentes". (BRASIL, 1996). Tais diretrizes, elaboradas por comissões de especialistas de cada área, estabelecem as competências e as habilidades a serem adquiridas pelos diferentes profissionais, além de indicar os conteúdos essenciais, os estágios curriculares, as atividades complementares e o trabalho de final de curso.

Sabe-se que as universidades gozam de autonomia didático-pedagógica, conforme consta no artigo 207 da Constituição Federal de 1988: "As universidades gozam de autonomia didático-pedagógica, administrativa e de gestão financeira e patrimonial, e obedecerão ao princípio da indissociabilidade entre o ensino, a pesquisa e a extensão" (BRASIL, 1996). No entanto, essas não podem se furtar de seguir as Diretrizes Curriculares Nacionais. Cabe, portanto, às universidades elaborar o projeto pedagógico dos seus cursos, tomando como 
base tais Diretrizes. Ao serem contempladas nos projetos pedagógicos, as Diretrizes Curriculares Nacionais irão nortear a formação dos profissionais no cotidiano da sala de aula e nos campos de estágio, o que significa a concretização das políticas educacionais formuladas para a educação superior no país.

Atender aos critérios estabelecidos pelas Diretrizes Curriculares Nacionais, no entanto, não significa que as universidades devam restringir-se a elas. É preciso levar igualmente em consideração as Diretrizes Institucionais para a formação de profissionais e o contexto social no qual irão atuar os futuros professores. $\mathrm{O}$ papel da universidade vai além do atendimento das demandas do mercado, tem como função primordial a formação para emancipação do ser humano.

Em relação à formação de professores ocorreu uma ampla discussão nos fóruns da área de educação. Tal preocupação procede uma vez que a formação dos profissionais da educação, na LDB, foi objeto de grandes mudanças, reservando-se para esta questão todo um título que engloba os artigos 61 a 67, além do artigo 87, parágrafo 4ํㅜ, que trata das exigências de formação superior dos professores. Em 2002, são aprovadas as Diretrizes Curriculares Nacionais para a Formação de Professores para a Educação Básica pela Resolução $\mathrm{CNE} / \mathrm{CP} \mathrm{n} \cong \mathbf{0}$ 1. Essas passam então a nortear a construção dos projetos pedagógicos dos cursos de formação de professores. Ao assumir o pressuposto de que cabe ao projeto pedagógico explicitar que tipo de profissional se pretende formar, delineando seu perfil a partir do contexto social no qual irá atuar, cabe a pergunta sobre que tipo de profissional da educação atende às exigências sociais contemporâneas.

Um projeto político-pedagógico tem como premissa a idéia de lançar-se para diante, rompendo com práticas, muitas vezes, calcadas em bases conservadoras e isto não ocorre num passe de mágica, daí a necessidade de constituir-se em uma construção participativa e democrática. Romper com 0 presente e projetar um futuro requer compromisso de todos os envolvidos com a educação. Significa que a gestão educacional deve ser participativa e democrática.

No Brasil, o modelo de gestão democrática está determinado no artigo 3.․ inciso oitavo da LDB no 9394/96, a qual indica que ensino será ministrado com base no princípio da "gestão democrática do ensino público, na forma desta Lei e da legislação dos sistemas de ensino". Sendo o princípio da participação enfatizado no artigo 14. ${ }^{\circ}$, da mesma lei a qual estabelece que "Os sistemas de ensino definirão as normas da gestão democrática do ensino público na educação básica, de acordo com as suas peculiaridades e conforme os seguintes princípios: I - participação dos profissionais da educação na elaboração do projeto pedagógico da escola; II - participação das comunidades escolar e local em conselhos escolares ou equivalentes. 


\section{A Trajetória das Pesquisas}

A fundamentação,o amadurecimento e a consolidação de uma gestão democrática e da formação de professores comprometidos com uma educação transformadora requerem a discussão que a pesquisa favorece, sobretudo nos trabalhos de teses e dissertações. Com o intuito de verificar o avanço teórico atingido na área de educação sobre a temática é que se buscou investigar a trajetória das pesquisas de dissertações e teses defendidas de 1999 a 2003 relacionados aos temas na Região Sul do Brasil. A fonte de referência básica da investigação são os resumos de dissertações e teses do período mencionado, que constam do Banco de Dados da CAPES.

Os dados da tabela 1 indicam o avanço da Pós-Graduação no Brasil na última década, por outro lado não se pode negar a influência da lógica capitalista adotada nos processos de controle e avaliação a que são submetidos os programas e seus pesquisadores.

\section{Tabela 1 - Total de Programas, Tese e Dissertações sobre Educação no Brasil e Região Sul - 1999 - 2003.}

\begin{tabular}{c|c|l|l|l|c}
\hline \multirow{2}{*}{ ANO } & $\begin{array}{l}\text { Número de } \\
\text { Programas } \\
\text { no Brasil }\end{array}$ & $\begin{array}{l}\text { Trabalhos na } \\
\text { área de } \\
\text { educação no } \\
\text { Brasil }\end{array}$ & $\begin{array}{l}\text { Média de } \\
\text { trabalhos por } \\
\text { programa no } \\
\text { Brasil }\end{array}$ & $\begin{array}{l}\text { Número de } \\
\text { Programas } \\
\text { na Região Sul }\end{array}$ & $\begin{array}{l}\text { Trabalhos na } \\
\text { área de } \\
\text { educação na } \\
\text { Região Sul }\end{array}$ \\
\hline 1999 & 48 & 1119 & 23,31 & 12 & 219 \\
2000 & 50 & 1480 & 29,76 & 14 & 347 \\
2001 & 59 & 1591 & 26,96 & 15 & 590 \\
2002 & 59 & 1992 & 33,76 & 17 & 536 \\
2003 & 64 & 2104 & 32,88 & 17 & $402 *$ \\
\hline TOTAL & $\mathbf{1 0 0 \%}$ & $\mathbf{8 2 8 6}$ & - & $\mathbf{2 6 , 5 7 \%}$ & $\mathbf{2 0 9 4}$ \\
\hline
\end{tabular}

Fonte: Organizada pelas autoras com base no Banco de Dados da CAPES - 2005.

O aumento no número de programas registrado no período de 19992003 foi significativo, tendo ocorrido um acréscimo de 33\%, e o número de teses e dissertações defendidas no período registra um acréscimo de $88 \%$. Isso indica um aumento de produtividade dos programas no período. Na análise desse dado é importante considerar a existência de programas novos, nos quais a produção ainda não está consolidada. 
*O número indicado em 2003, no total de trabalhos da Região Sul, não corresponde ao número total de trabalhos defendidos, pois os dados sobre as defesas realizadas em três programas não estavam disponibilizados no Banco de Dados da CAPES na época da consulta. Trata-se dos seguintes programas: PUC/RS, UPF e UTP, nos quais a produção é significativa. Os Programas da Região Sul correspondem a 26,57\% dos Programas Nacionais e a produção, mesmo sem serem computados os dados dos três programas mencionados, pelo número de trabalhos corresponde à 25,28\% da produção nacional em termos de teses e dissertações defendidas.

\section{Tabela 2 - Total de Programas, Tese e Dissertações sobre Educação e Políticas e Gestão da Educação na Região Sul do Brasil por IES - 1999 - 2003}

\begin{tabular}{l|c|c|c|c|c}
\hline \multicolumn{2}{c|}{ PROGRAMAS } & $\begin{array}{c}\text { Área Educ. } \\
\text { 1999-2003 }\end{array}$ & Do tema 1999-2003 & $\begin{array}{c}\text { \% teses e dissert. do } \\
\text { tema 1999-2003 }\end{array}$ \\
\hline IES & Estado & Nível & & & 52,00 \\
UFPEL & RS & M & 100 & 52 & 16,72 \\
UFRGS & RS & D/M & 287 & 48 & 19,41 \\
PUC/RS & RS & D/M & 170 & 33 & 43,70 \\
UFSM & RS & M & 151 & 66 & 52,94 \\
UNISINOS & RS & M & 85 & 45 & 20,00 \\
UNIJUI & RS & M & 110 & 22 & 23,07 \\
UPF & RS & M & 65 & 15 & $* 9,52$ \\
FURG & RS & M & 63 & 06 & Média: 27,83 \\
Subtotal & & & 1031 & 287 & 43,12 \\
UFSC & SC & D/M & 211 & 91 & 29,03 \\
FURB & SC & M & 62 & 18 & 12,90 \\
UNIVALI & SC & M & 93 & 12 & Média: 33,06 \\
Subtotal & & & 366 & 121 & 38,52 \\
PUCPR & PR & M & 122 & 47 & 15,78 \\
UEL & PR & M & 57 & 9 & 13,97 \\
UEM & PR & M & 93 & 13 & 60,86 \\
UEPG & PR & M & 46 & 28 & 50,00 \\
UTP & PR & M & 20 & 10 & 13,26 \\
UFPR & PR & D/M & 196 & 26 & Média Geral: 28,59 \\
Subtotal & - & - & 534 & 133 & \\
\hline TOTAL & & & $* * 1931$ & $\mathbf{5 4 1}$ & \\
\hline
\end{tabular}

Fonte: Organizada pelas autoras com base no Banco de Dados da CAPES - 2005. 
Conforme apresentado na tabela 2, a média do percentual de trabalhos de teses e dissertações da área de educação que tratam da temática políticas, gestão e formação de professores é significativa na Região Sul. Contudo merecem destaque os índices apresentados na UEPG, UNISINOS, UFPEL, UTP, UFSM, UFSC e PUCPR.

O programa da FURG tem como área de concentração e quatro linhas de pesquisa em Educação Ambiental. O número total de teses e dissertações disponibilizados e analisados na região foi de 1931, sendo que o número total dos trabalhos defendidos segundo os dados da CAPES foi de 2094. Essa diferença de 163 trabalhos se referem aos trabalhos não informados/disponibilizados em 2003 pelos programas já mencionados. Assim, é possível deduzir que em 2003 na Região Sul foram defendidos 565 trabalhos.

\section{Tabela 3 - Distribuição da Produção de Mestrandos e Doutorandos sobre Temas Abordados em Políticas e Gestão da Educação na Região Sul do Brasil - 1999-2003}

\begin{tabular}{l|c|c|c|c|c}
\hline PROGRAMAS & $\begin{array}{c}\text { Políticas } \\
\text { Educacionais }\end{array}$ & $\begin{array}{c}\text { Gestão } \\
\text { Educacional }\end{array}$ & $\begin{array}{c}\text { Gestão } \\
\text { Democrática }\end{array}$ & $\begin{array}{c}\text { Projeto } \\
\text { Pedagógico/ } \\
\text { Currículo }\end{array}$ & $\begin{array}{c}\text { Formação de } \\
\text { Profess ores }\end{array}$ \\
\hline UFPEL & 9 & - & 1 & 8 & 26 \\
UFRGS & 9 & 7 & 1 & 11 & 20 \\
PUC/RS & 2 & 14 & 1 & 2 & 14 \\
UFSM & 4 & 3 & 1 & 10 & 48 \\
UNISINOS & 3 & 4 & 4 & 10 & 21 \\
UNIJUI & 9 & - & - & 1 & 12 \\
UPF & 4 & - & 2 & 2 & 7 \\
FURG & - & - & - & 2 & 4 \\
Subtotal & 40 & 28 & 10 & 46 & 152 \\
UFSC & 23 & 18 & 5 & 8 & 37 \\
FURB & 1 & 6 & 3 & 3 & 5 \\
UNIVALI & - & 3 & 1 & 4 & 4 \\
Subtotal & 24 & 27 & 9 & 15 & 46 \\
PUCPR & 13 & 10 & 2 & 15 & 16 \\
UEL & - & - & 1 & 8 & 3 \\
UEM & 9 & 2 & 4 & 1 & - \\
UEPG & 3 & 5 & 3 & 4 & 13 \\
UTP & 2 & 2 & 1 & 6 & 1 \\
UFPR & 14 & 4 & 3 & 5 & 8 \\
Subtotal & 41 & 23 & 14 & 39 & 41 \\
TOTAL & 105 & 78 & 33 & 100 & 239 \\
\% & 18 & 14,1 & 6,0 & 18,0 & 43,0 \\
\hline
\end{tabular}

Fonte: Organizada pelas autoras com base no Banco de Dados da CAPES - 2005. 
A análise dos dados, apresentados na tabela 3, apoiou-se nas palavras-chave e títulos das teses e disssertações de 1999-2002 e nas palavraschave, título e resumos em 2003. Foi possível observar pela leitura dos resumos que nem todos os trabalhos que anunciam uma palavra-chave de fato contempla a investigação daquele item. Por exemplo, na palavra-chave formação de professores, um grande número de trabalhos a indica e na verdade a investigação não trata especificamente da formação de professores, mas sim de metodologias e saberes da ação docente, entre outros. Contudo, a análise adotou como categoria/ critério de análise as palavras-chave, título entre 19992002, acrescidas dos resumos em 2003. Assim tais trabalhos também são considerados como referentes ao tema. Percebe-se a necessidade de um maior rigor na indicação das palavras-chave nos trabalhos científicos.

A distribuição das pesquisas realizadas no período, com base nas palavras-chave analisadas indica uma predominância de estudos em formação de professores, em 43\%. Esse aspecto se justifica em face da ampla discussão que a formação de professores mereceu nos últimos anos, sobretudo, após aprovação da $\mathrm{LDB}$ n- 9394/96. A forma como a LDB trata a questão gerou grande polêmica entre os educadores.

Os estudos que tratam as políticas educacionais e a questão do projeto pedagógico/currículo são significativos e sua distribuição está praticamente igual nos programas, apresentando 18,9\% e 18,0\% respectivamente. Contudo uma questão que merece igual ênfase nos estudos que é a gestão educacional tem uma incidência de $14,1 \%$ nos estudos. Os dados indicam uma necessidade de ampliação dos estudos no que se refere ao modelo de gestão democrática, cujo percentual é de apenas $6 \%$. A pequena incidência de investigação nessa temática preocupa em face de sua relevância na formação e na atuação dos profissionais da educação, sobretudo o professor, em virtude do que determinam as atuais políticas educacionais.

\section{Apontamentos para uma Reflexão Final}

O estudo contribui na produção do estado da arte da investigação sobre a temática e possibilita estabelecer apontamentos para pesquisas futuras que busquem discutir as políticas educacionais e contribuam para consolidar a gestão democrática da escola e aperfeiçoar a formação de professores.

As mudanças ocorridas na última década têm como decorrência significativas alterações nas políticas educacionais e nas práticas no cotidiano da escola. Dessas merecem destaque as novas formas como se vêm buscando realizar o exercício da gestão educacional. Cabe ressaltar que os rumos da escola refletem as contradições e os interesses em jogo na sociedade. Não se 
pode esperar unanimidade e tampouco uma transição rápida e sem conflitos, pois há necessidade do amadurecimento da reflexão e da ação coletiva para que se efetive a transição do modelo de gestão centralizada para 0 modelo de gestão participativa. Para isto se faz necessária a consolidação de um referencial teórico-prático, cuja construção pode ser favorecida mediante realização de pesquisas por meio da realização de teses e dissertações.

Essa temática envolve o conjunto dos profissionais da educação, assim é vital que a sua reflexão perpasse a formação de mestres e doutores em educação e, sobretudo, a formação de professores. Em conformidade com as políticas educacionais em vigência no Brasil, os pressupostos teórico-práticos mobilizados na gestão democrática da escola são sistematizados de forma participativa no seu projeto pedagógico. Contudo, observa-se uma grande dificuldade na operacionalização de tal modelo nas escolas, tanto na educação básica quanto na educação superior. Além das dificuldades existentes nas próprias escolas em que faltam atividades e programas destinados a estudos e reflexão sobre a prática, bem como a oferta de programas de formação continuada aos professores, para que um novo modelo de gestão educacional seja posto em prática, é imprescindível a construção de um referencial teórico sólido e amplo, pautado na ação-reflexão-ação coletiva. É possível constatar que a aceitação da participação em processos decisórios democráticos na gestão do projeto pedagógico na escola pode ser considerada como tendência dominante nos discursos dos profissionais da área. Contudo a sua concretização no espaço escolar ainda tem um grande caminho a ser percorrido.

Todos os profissionais da educação possuem atribuições e responsabilidades que se integram e se complementam na gestão da escola. 0 projeto como processo é fruto da ação-reflexão-ação coletiva, ou seja, implica na construção conjunta da unidade da ação orientada no princípio da participação. Nesse sentido e, em conformidade com a determinação da LDB no 9394/96, a gestão do projeto da escola é responsabilidade compartilhada, de maneira que todos os profissionais da escola estão envolvidos na gestão educacional.

O desafio posto está na consolidação de uma concepção de gestão cuja finalidade está em promover uma ação coletiva que viabilize uma formação de qualidade do profissional, capaz de interagir num contexto caracterizado pela complexidade e em transformação. Para tanto, cada profissional da educação é instigado a desenvolver capacidade de articulação e a liderança na tomada de decisão, o que exige visão interdisciplinar, compromisso com uma gestão participativa e capacidade para aprender coisas novas, de análise e de julgamento no enfrentamento dos desafios individuais e coletivos. 


\section{Referências}

AZEVEDO, J. M. L A educação como política pública. 2. ed. Campinas: Autores Associados, 2001.

BRASIL. Lei de Diretrizes e Bases da Educação Nacional. Lei 9394/96. Publicado em Diário Oficial da União, 26 dez. 1996.

BRASIL. Constituição da República Federativa do Brasil. Diário Oficial da União. Brasília: Imprensa Nacional, 5 out.1988, 1998.

BRASIL. Ministério da Educação. Resolução CP/CNE no 01/2002. Diretrizes Curriculares Nacionais para a Formação de Professores da Educação Básica, em nível superior, curso de licenciatura, de graduação plena. Brasília, 2002. Disponível em: http://www.mec.gov.br. Acessado em: 08 out. 2006.

BRASIL.(2005). CAPES.MEC. Banco de dados da CAPES: resumos de dissertações e teses - 1999-2003. Disponível em: http:// acessolivre.capes.gov.br. Acessado em: 08 out. 2006.

DOURADO, L. F.; CATANI, A. M.; OLIVEIRA, João F. Transformações recentes e debates atuais no campo da educação superior no Brasil. In: DOURADO, L. F.; CATANI, A M.; OLIVEIRA, J. F. Políticas e gestão da educação superior: transformações recentes e debates atuais. São Paulo: Xamã; Goiânia: Alternativa, 2003.

GOMES, A. M. Estado, mercado e educação superior no Brasil: um modelo analítico. Educação e Sociedade, Campinas, v. 24, n. 84m, p. 839-872, 2004.

GOMEZ, J. M. Política e democracia em tempos de globalização. Petrópolis: Vozes, 2000.

LOBATO, L. V. C. Avaliação das políticas sociais: notas sobre alguns limites e possíveis desafios. Trabalho, Educação e Saúde, v. 2, n. 1, p. 95-106, Rio de janeiro, 2004.

RAMOS, M. N. A pedagogia das competências: autonomia ou adaptação?São Paulo: Cortez, 2001. 